\title{
Crescimento e alterações morfológicas no intestino de tilápia do Nilo (Oreochromis noloticus): diminuição da farinha de peixe em dietas com níveis de proteína bruta
}

\author{
[Growth and intestinal morphology in Nile tilapia (Oreochromis noloticus): decrease in fishmeal in \\ diets with crude protein levels]
}

\section{"Artigo Científico/Scientific Article"}

\author{
Claucia Aparecida Honorato ${ }^{1 *}$, Rebeca Maria Souza ${ }^{1}$, Rudã Fernandes Brandão Santos ${ }^{2}$, Dacley \\ Herts Neu ${ }^{1}$, Dalton José Carneiro ${ }^{3}$
}

\begin{abstract}
${ }^{1}$ Faculdade de Ciências Agrárias, Universidade Federal da Grande Dourados, Dourados-MS, Brasil.
${ }^{2}$ Laboratório de Enzimologia, Departamento de Bioquímica, Universidade Federal de Pernambuco, Recife-PE, Brasil. ${ }^{3}$ Departamento de Zootecnia, Faculdade de Ciências Agrárias e Veterinárias, Universidade Estadual Paulista, JaboticabalSP, Brasil.

*Autora para correspondência/Corresponding author: E-mail: clauciahonorato@ufgd.edu.br
\end{abstract}

\section{Resumo}

Objetivou-se com este trabalho avaliar o efeito da diminuição de farinha de peixe em dietas com níveis de proteína bruta sobre o desempenho zootécnico, eficiência de retenção de nutrientes e histologia do intestino de tilápia do Nilo (Oreochromis niloticus). Foram utilizados 180 alevinos de tilápia com o peso inicial de 1,17 \pm $0,05 \mathrm{~g}$, distribuídos em 18 aquários por um período de 75 dias. Os resultados foram analisados por meio de um Delineamento Inteiramente Casualizado - DIC, com seis tratamentos em esquema fatorial 3x2, correspondendo três níveis de proteína bruta das dietas $(20 \%, 24 \%$ e $28 \%)$ e dois níveis de inclusão de farinha de peixe - FP ( $25 \%$ ou $50 \%$ do nível de proteína da dieta), com três repetições. Quando a análise de variância mostrou diferenças significativas entre tratamentos, as médias foram comparadas pelo teste Tukey. Foram avaliados o desempenho de produção e a eficiência de retenção de nutrientes e as alterações na histologia e altura das vilosidades intestinais. $\mathrm{O}$ aumento de proteína na dieta proporcionou aumento no ganho em peso e na taxa de crescimento específico. As dietas com níveis de proteína de $28 \%$ promovem balanço de nutrientes ao ponto de diminuir a inclusão de farinha de peixe $(25 \%)$, refletindo em melhores índices de desempenho produtivo e adaptações na morfologia do trato digestórios de tilápia do Nilo. As alterações histomorfométricas estão relacionadas à alimentação fornecida e representam uma resposta adaptativa ao metabolismo. Conclui-se que para juvenil de tilápia, as dietas com $28 \%$ de proteína bruta podem diminuir a inclusão de farinha de peixe (25\%), refletindo em melhores índices de desempenho produtivo e adaptações na morfologia do trato digestórios.

Palavras-chave: histologia; fontes de proteína; nutrição de peixes.

\begin{abstract}
The objective of this work was to evaluate the effect of the decrease of fishmeal in diets with crude protein levels on performance, nutrient retention efficiency, and intestinal histology in the Nile tilapia (Oreochromis niloticus). We used 180 tilapia fingerlings with an initial weight of $1.17 \pm 0.05 \mathrm{~g}$, distributed in 18 aquariums for 75 days. The results were analyzed in a completely randomized design, with six treatments in a $3 \times 2$ factorial, corresponding to three crude protein levels in the diets $(20 \%, 24 \%$ and $28 \%)$ and two levels of inclusion of fishmeal - FP (25\% or $50 \%$ of the protein level of the diet), with three replications. When the analysis of variance showed significant differences between treatments, the means were compared by the Tukey test. Production performance and nutrient retention efficiency and changes in histology and height of intestinal villi were evaluated. The increase in protein in the diet provided an increase in weight gain and the specific growth rate. Diets with protein levels of $28 \%$ promote nutrient balance to the point of decreasing the inclusion of fishmeal (25\%), reflecting better productive performance indexes and adaptations in the morphology of the digestive tract of Nile tilapia. Histomorphometric changes are related to the diet provided and represent an adaptive response to metabolism. It was concluded that juvenile tilapia diets with $28 \%$ crude
\end{abstract}


protein can decrease the inclusion of fishmeal (25\%), reflecting better productive performance indexes and adaptations in digestive tract morphology

Keywords: histology; protein sources; fish nutrition.

\section{Introdução}

No Brasil, a principal cadeia produtiva de peixes cultivados é a da tilápia (Honorato et al., 2014), portanto, é natural que esforços sejam direcionados para otimização de sua produtividade. Dentre os pontos mais onerosos da cadeia produtiva do pescado está a alimentação (Cyrino et al., 2010). As dietas na aquicultura apresentam particularidades como alto percentual de proteína e de quantidade da farinha de peixe em sua formulação (Assano et al., 2011).

A farinha de peixe é o ingrediente de predileção na formulação de organismos aquáticos. Apresenta um excelente perfil de aminoácidos e de ácidos graxos essenciais (Moutinho et al., 2017. No entanto é um ingrediente cada vez mais escasso pela demanda da indústria de rações como pela diminuição dos estoques naturais de peixes (Han et al., 2018). Diversos estudos abordaram a utilização racional da farinha de peixe (FP) em dietas práticas (Deng et al., 2017; Moutinho et al., 2017; Khalifa et al., 2018), no entanto ainda há lacunas no que tange a formulações e adequações dos ingredientes (Koch et al., 2016). A substituição total da farinha de peixe por proteína de origem vegetal necessita da inclusão de aminoácidos industriais para suprimir qualquer efeito negativo ao desempenho e higidez dos animais ( $\mathrm{Li}$ et al., 2009).

A tendência atual na produção de rações para peixes é obter o equilíbrio entre inclusão de farinha de peixe na dieta ao mínimo necessário para alta performance de crescimento. No entanto, para compreender a exigência nutricional para adequado desempenho e saúde dos peixes faz-se necessário a utilização de ferramentas como a histologia da mucosa intestinal (Romarheim et al., 2008; Ota et al., 2019). O desenvolvimento dos organismos aquáticos é o reflexo da eficiência de utilização dos alimentos consequência das adaptações morfológicas do trato digestório em função a dieta ofertada (Awad et al., 2013; Ota et a., 2019).

Objetivou-se com este trabalho avaliar o efeito da diminuição de farinha de peixe em dietas com níveis de proteína bruta sobre o desempenho zootécnico, eficiência de retenção de nutrientes e histologia do intestino de tilápia do Nilo (Oreochromis niloticus).

\section{Material e Métodos}

Foram utilizados 180 alevinos de tilápia com o peso médio inicial de $1,17 \pm 0,05 \mathrm{~g}$, distribuídos em 18 aquários com capacidade de $150 \mathrm{~L}$, abastecidos continuamente com água proveniente de poço artesiano, com troca de aproximadamente 20 vezes ao dia e aeração constante, por um período de 75 dias. A qualidade da água monitorada durante o período experimental apresentou as médias de oxigênio dissolvido de 5,70 $\pm 0,2 \mathrm{mg}$ de $\mathrm{O}_{2} \mathrm{~L}^{-1}$, temperatura de $29,27 \pm 1,20{ }^{\circ} \mathrm{C}, \mathrm{pH}$ de 7,95 $\pm 0,03$ e condutividade elétrica de $127,17 \pm 0,04$ $\mu \mathrm{S} . \mathrm{cm}^{-1}$.

O experimento foi conduzido em um delineamento inteiramente casualizado em esquema fatorial $3 \times 2$, correspondendo a três níveis de proteína bruta nas dietas e dois níveis de inclusão de farinha de peixe (FP), com três repetições, perfazendo um total de 18 unidades experimentais, contendo 10 peixes em cada aquário.

As dietas (Tabela 1) foram formuladas para apresentar três níveis de proteína bruta $(20,24$ e $28 \%$ ), e duas porcentagens de inclusão de farinha de peixe ( 25 ou $50 \%$ do nível de proteína da dieta), de acordo com as análises prévias dos ingredientes (AOAC., 2000).

As rações foram peletizadas em máquina de moer carnes (California Pellet Mill) e posteriormente, secas e conservadas em freezer. $\mathrm{O}$ arraçoamento foi fornecido à vontade, duas vezes ao dia (manhã e tarde) em pequenas quantidades até a saciedade aparente.

Foram mensurados a quantidade de peixes para sobrevivência e o ganho em peso individual em balança analítica a cada 25 dias para avaliação do crescimento. Antes de cada biometria os peixes permaneceram em jejum por 24 horas para o esvaziamento gástrico. Ao final do experimento, foram avaliados: ganho de peso $(\mathrm{GP}=$ peso final - peso inicial), taxa de crescimento específico $\left(\% \cdot \operatorname{dia}^{-1}\right)=(\mathrm{TCE}=100[(\ln$ peso final médio $-\ln$ peso inicial médio)/tempo]); conversão alimentar aparente $(\mathrm{CAA}=$ consumo de ração/ganho de peso); Consumo de dieta $(\mathrm{g})=(\mathrm{CD}=$ consumo de dieta/ tempo experimental) e Taxa de Eficiência 
Protéica $=(\mathrm{TEP}=[$ ganho em peso úmido/proteína consumida).

Para a análise de composição corporal foram coletados 10 alevinos, de uma amostra inicial, e ao final do período experimental três peixes de cada unidade experimental perfazendo um total de nove peixes por tratamento. Os animais permaneceram em jejum de 48 horas e após foram abatidos (com imersão em gelo) congelados. Posteriormente, as amostras foram moídas e secas em estufa a $105^{\circ} \mathrm{C}$, até peso constante para análises de proteína bruta e extrato etéreo (AOAC, 2000). A energia bruta foi determinada através da queima em bomba calorimétrica (Parr Instruments Company).

Tabela 1. Formulação e composição química das dietas experimentais utilizadas na alimentação de tilápia do Nilo (Oreochromis niloticus).

\begin{tabular}{|c|c|c|c|c|c|c|}
\hline \multirow{2}{*}{$\begin{array}{l}\text { Níveis de proteína } \\
\text { Proporção de farinha de peixe* }\end{array}$} & \multicolumn{2}{|c|}{$20 \%$ PB } & \multicolumn{2}{|c|}{$24 \%$ PB } & \multicolumn{2}{|c|}{$28 \%$ PB } \\
\hline & $25 \%$ & $\mathbf{5 0 \%}$ & $25 \%$ & $50 \%$ & $25 \%$ & $50 \%$ \\
\hline \multicolumn{7}{|l|}{ Ingredientes (\%) } \\
\hline Farinha de peixe & 8,3 & 16,6 & 10 & 20 & 11,6 & 23,3 \\
\hline Milho moído & 47 & 50,9 & 36,5 & 60,7 & 25,9 & 31,3 \\
\hline Farelo de soja & 13,3 & 1,7 & 22 & 12,9 & 30,6 & 14,3 \\
\hline Farelo de trigo & 25 & 25 & 25 & 25 & 25 & 25 \\
\hline Quirera de arroz & 5 & 5 & 5 & 5 & 5 & 5 \\
\hline Óleo de soja & 0,6 & 0,1 & 0,9 & 0,5 & 1,2 & 0,4 \\
\hline Suplemento vitamínico ${ }^{1}$ & 0,4 & 0,4 & 0,4 & 0,4 & 0,4 & 0,4 \\
\hline Suplemento Mineral $^{2}$ & 0,3 & 0,3 & 0,3 & 0,3 & 0,3 & 0,3 \\
\hline \multicolumn{7}{|l|}{ Composição Calculada } \\
\hline Matéria seca (\%) & 92,6 & 93,2 & 92,3 & 93 & 92 & 92,9 \\
\hline Proteína bruta (\%) & 20 & 20 & 24 & 24 & 28 & 28 \\
\hline Extrato etéreo (\%) & 4,5 & 4,5 & 4,5 & 4,5 & 4,5 & 4,5 \\
\hline Energia bruta (kcal.kg-1) & 4219 & 4182 & 4261 & 4216 & 4303 & 4251 \\
\hline \multicolumn{7}{|c|}{$\begin{array}{l}{ }^{1} \text { Composição do suplemento mineral e vitamínico: Ferro } 15.000 \mathrm{mg} \text {, Cobre } 5.000 \mathrm{mg} \text {, Iodo } 500 \mathrm{mg} \text {, Manganês } 17.000 \mathrm{mg} \text {, Zinco } \\
12.000 \mathrm{mg} \text {, Selênio } 70 \mathrm{mg} \text {, veículo } 1000 \mathrm{~g} \text {, Vitamina A } 12.000 \mathrm{UI} \text {, Vitamina D3 } 1500 \mathrm{UI} \text {, Vitamina E } 50 \mathrm{mg} \text {, Vitamina K } 4 \mathrm{mg} \text {, } \\
\text { Vitamina B12 } 7 \mathrm{mg} \text {, Vitamina B2 } 7 \mathrm{mg} \text {, Ácido pantotênico } 60 \mathrm{mg} \text {, Ácido nicotínico } 120 \mathrm{mg} \text {, Cloreto de colina } 600 \mathrm{mg} \text {, Metionina } 700 \\
\mathrm{mg} \text {, Antioxidante } 500 \mathrm{mg} \text {, Veículo } 1000 \mathrm{~g} \text {. }{ }^{2} \text { Composição calculada com base nos dados obtidos em análises realizadas no Laboratório } \\
\text { de Nutrição de Organismos Aquáticos do CAUNESP, Jaboticabal, segundo AOAC (2000). } \\
\text { *PFP - Proporção de Farinha de peixe } \\
\text { 25\% do teor de proteína da dieta; } 50 \% \text { do teor de proteína da dieta. }\end{array}$} \\
\hline
\end{tabular}

Os resultados da análise de composição corporal foram utilizados nos cálculos de eficiência de retenção de proteína bruta $\left(\mathrm{ER}_{\mathrm{PB}}\right)$; Proteína bruta no ganho em peso $\left(\mathrm{PB}_{\mathrm{GP}}\right)$; Eficiência de retenção de energia bruta $\left(\mathrm{ER}_{\mathrm{EB}}\right)$ e Extrato etéreo no ganho em peso $\left(\mathrm{EE}_{\mathrm{GP}}\right)$, de acordo com as equações: Eficiência de retenção (ER): $\mathrm{ER}=[(\mathrm{M}$ final $\mathrm{x}$ peso final) - ( $M$ inicial $x$ peso inicial) $/ M$ ingerida] 100 ; Porcentagem no ganho em peso (\%GP): \%GP = [( $\mathrm{M}$ final - peso médio final) ( $\mathrm{M}$ inicial - peso médio inicial) /peso final - peso inicial]100. Onde M é o teor médio (\%) de proteína, energia bruta ou extrato etéreo corporal dos peixes na matéria seca, e peso final e inicial referem-se aos pesos $(\mathrm{g})$ dos peixes no início e ao final do experimento.

Foram separados nove exemplares de cada tratamento para retirada de amostras do intestino anterior (compreendendo a parte do jejuno em animais mamíferos) para as análises histológicas e análise histoquímica. Posteriormente, as amostras foram fixadas em solução de Bouin, por 24 horas.
Após a fixação, procedeu-se à lavagem em álcool $70 \%$ em série alcoólica crescente, diafanização em série de xilóis, inclusão em paraplasti e cortados em espessura variando entre $5 \mu \mathrm{m}$ de espessura. Para cada tratamento (dieta experimental) foram produzidas três lâminas por peixe com total de 27 lâminas por tratamento. A coloração das lâminas foi realizada pela técnica Hematoxilina - Eosina. Foi realizada a mensuração da altura das vilosidades intestinais. Para realização da histoquímica utilizou-se os métodos de PAS/H (Ácido periódico de Shiff), Alcian-Blue PAS, Alcian-Blue $\mathrm{pH} 0,5$ e $\mathrm{pH}$ 2,5. O material foi analisado e fotodocumentado em fotomicroscópio Axioskop- Zeiss.

Os dados foram submetidos à análise de variância (ANOVA) e quando houve diferenças significativas entre os tratamentos $(\mathrm{P}<0,05)$, as médias foram comparadas pelo teste Tukey por meio da análise de diferenças mínimas significativas DMS. 


\section{Resultados}

Não houve diferenças significativas na sobrevivência bem como no consumo da dieta, o que demonstra a boa aceitabilidade das dietas com menor percentual de farinha de peixe. $\mathrm{O}$ desenvolvimento dos peixes apresentou interação entre os níveis de proteína e a proporção de farinha de peixe utilizada (Tabela 2).

Para os tratamentos com a inclusão da FP em $25 \%$ do teor de proteína da dieta, o incremento de proteína proporcionou aumento no ganho em peso (Figura 1A) e na taxa de crescimento específico (Figura 1B). Nas dietas com $28 \%$ de proteína o aumento da inclusão da FP em 50\% da proteína da ração acarretou os menores valores de ganho em peso e taxa de crescimento específico. Enquanto a utilização da FP em $50 \%$ do teor de proteína da dieta na foi de fundamental importância para as dietas com baixo nível de proteína (20\% PB) para TCE (Figura 1B).

Tabela 2. Desempenho produtivo de tilápia do Nilo (Oreochromis niloticus) alimentadas com diferentes dietas com farinha de peixe.

\begin{tabular}{|c|c|c|c|c|c|}
\hline Tratamentos & GP & TCE & $\mathbf{C A}$ & CT & TEP \\
\hline \multicolumn{6}{|l|}{ Níveis de proteína $(P B)$} \\
\hline 20 & 18,91 & 3,80 & 2,36 & 43,54 & 2,20 \\
\hline 24 & 20,57 & 3,88 & 2,18 & 45,03 & 2,20 \\
\hline 28 & 21,45 & 3,98 & 2,07 & 43,10 & 2,19 \\
\hline \multicolumn{6}{|l|}{ Proporção de farinha de peixe (PFP) } \\
\hline $25 \%$ & 20,96 & 3,89 & 2,30 & 46,44 & 2,19 \\
\hline $50 \%$ & 19,66 & 3,88 & 2,11 & 41,34 & 2,20 \\
\hline \multicolumn{6}{|l|}{ Valores F (Anova) } \\
\hline Niveis de proteína $(P B)$ & 2,15 & $4,19 *$ & 0,98 & 0,18 & 0,09 \\
\hline Proporção de farinha de peixe (PFP) & 1,65 & 0,04 & 1,34 & 3,48 & 0,37 \\
\hline$P B \times P F P$ & $4,84 *$ & $11,07 * *$ & 1,58 & 0,31 & 4,22 \\
\hline Coeficiente de variação (\%) & 10,55 & 2,74 & 16,3 & 13,19 & 17,54 \\
\hline
\end{tabular}

$*(\mathrm{P}<0,05) ; * *(\mathrm{P}<0,01)$. GP - ganho em peso $(\mathrm{g})$, TCE - taxa de crescimento específico $\left(\%\right.$ ao dia $\left.^{-1}\right)$, CA - conversão alimentar, CT- consumo de dieta (g), TEP - taxa de eficiência proteica (\%).

A

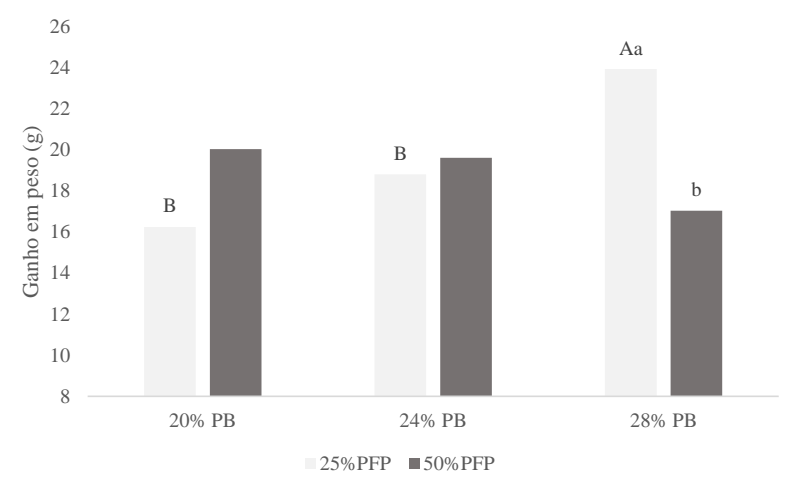

B

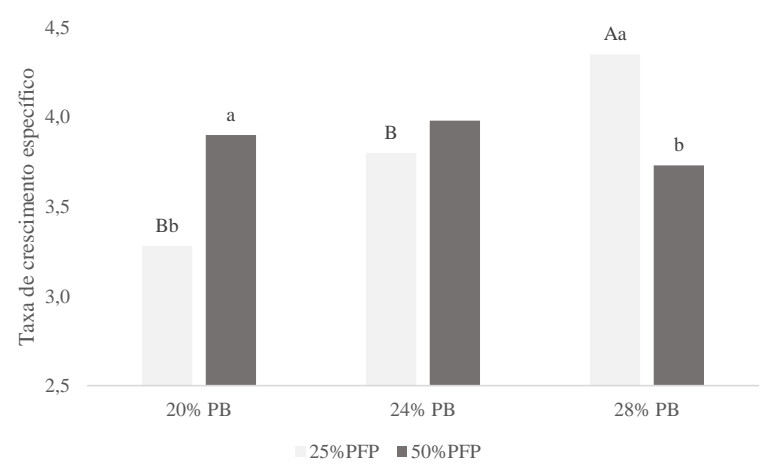

Figura 1. Interação entre níveis de proteína bruta e proporção de farinha de peixe em dietas para tilápia do Nilo (Oreochromis niloticus) (A) ganho em peso e (B) taxa de crescimento específico. Letras diferentes (maiúscula para níveis de proteína e minúscula proporção de farinha de peixe) reportam diferença significativa pelo teste de Tukey $(\mathrm{P}<0,05)$. *PFP - Proporção de Farinha de peixe: $25 \%$ do teor de proteína da dieta; $50 \%$ do teor de proteína da dieta.

Os parâmetros de eficiência de retenção de nutrientes não apresentaram diferenças significativas para os níveis de proteína das dietas. O percentual de inclusão de farinha de peixe na dieta proporciona maior retenção de proteína bruta (Tabela 3).
A histologia não demonstrou diferença nas estruturas do intestino de tilápia do Nilo quando submetido aos diferentes regimes alimentares propostos (Figura 2). 
Tabela 3. Eficiência de retenção de proteína, energia e extrato etéreo e porcentagem de proteína no ganho em peso de tilápias do Nilo (Oreochromis niloticus) alimentadas com diferentes dietas com farinha de peixe.

\begin{tabular}{|c|c|c|c|c|}
\hline Tratamentos & ERPB & $\mathbf{P B}_{\mathrm{GP}}$ & $\mathbf{E R}_{\mathbf{E B}}$ & $\mathbf{E E}_{\mathrm{GP}}$ \\
\hline \multicolumn{5}{|l|}{ Níveis de proteína } \\
\hline 20 & 48,2 & 30,0 & 45,9 & 22,0 \\
\hline 24 & 46,5 & 29,3 & 48,7 & 22,2 \\
\hline 28 & 46,0 & 29,9 & 49,5 & 21,2 \\
\hline \multicolumn{5}{|l|}{ Proporção de farinha de peixe } \\
\hline $25 \%$ & $44,7 \mathrm{~b}$ & 29,25 & 46,9 & 22,27 \\
\hline $50 \%$ & $47,6 \mathrm{a}$ & 30,25 & 49,14 & 21,31 \\
\hline \multicolumn{5}{|l|}{ Valores F (Anova) } \\
\hline Níveis de proteína $(P B)$ & 1,6 & 0,8 & 2,3 & 0,9 \\
\hline Proporção de farinha de peixe (PFP) & $16,2^{* *}$ & 5,9 & 2,4 & 3,2 \\
\hline $\mathrm{PB} \times \mathrm{PFP}$ & 0,3 & 0,1 & 0,6 & 0,2 \\
\hline Coeficiente de variação (\%) & 22,05 & 13,78 & 21,31 & 27,26 \\
\hline
\end{tabular}

A histologia do intestino de tilápia do Nilo revelou que a mucosa exibiu um epitélio prismático simples composto por enterócitos entremeados por células caliciformes PAS (positivo), AB (positivo) em $\mathrm{pH}$ 0,5 e 2,5 e PAS/AB (positivo), indicando a secreção de glicoproteínas neutras e mucosubstâncias ácidas sulfatadas e carboxiladas e glicoconjugadas. A submucosa apresentou tecido conjuntivo frouxo PAS (positivo). Observou-se que a variação da intensidade de secreção de mucosubstâncias (glicoproteínas) pelas células caliciformes apresentou-se diretamente correlacionada com o tipo de dieta ofertada aos peixes. A secreção de mucosubstâncias ácidas e glicoconjugadas (PAS/AB) apresentaram o mesmo padrão para os peixes que receberem as dietas contendo diferentes níveis de farinha de peixe (Tabela 4). Estes resultados inferem que a presença da farinha de peixe na dieta promove maior resposta de secreção das células caliciformes como efeito benéfico para digestão desta fonte de proteína. $\mathrm{O}$ aumento de proteína na dieta refletiu em aumento na altura da vilosidade intestinal. A elevação de 25 para 50\% PFP não alterou a altura das vilosidades intestinais destes peixes.

\section{Discussão}

A farinha de peixe é uma ótima fonte proteica para organismos aquáticos, porém, seu elevado custo (Koch et al., 2016) vem contribuindo para que pesquisadores procurem fontes alternativas para sua substituição às rações, ou reduzam suas proporções na dieta (Moutinho et al., 2017), sem que isso ocasione em redução no desempenho zootécnico. Boscolo et al. (2001) relatam que os alimentos de origem animal, como a farinha de peixe, são classificados como atractopalatabilizantes, que possuem capacidade de atrair o peixe até a ração e estimular seu consumo (Rodrigues et al., 2015). A diminuição da inclusão da farinha de peixe na dieta para tilápia do Nilo não influenciou no consumo. A indicação de que as fontes de proteína não interferiram no consumo da dieta de tilápia do Nilo quando submetidos a diferentes fontes de proteína de origem animal foi constatada por Boscolo et al. (2001) e por Assano et al. (2011).

A eficiência no desempenho zootécnico promovido pela inclusão de farinha de peixe pode estar relacionada ao aumento do conteúdo de lisina e metionina da farinha de peixe e sua boa disponibilidade (Boscolo et al., 2008) para tilápias. De acordo com o NRC (2011), a utilização de várias fontes proteicas é uma forma de fazer uma mistura de aminoácidos para evitar o desbalanço, e consequentemente, proporcionar maior crescimento aos peixes, fato que pode contribuir para os resultados obtidos quando incluído farinha de peixe em $25 \%$ da proteína. 

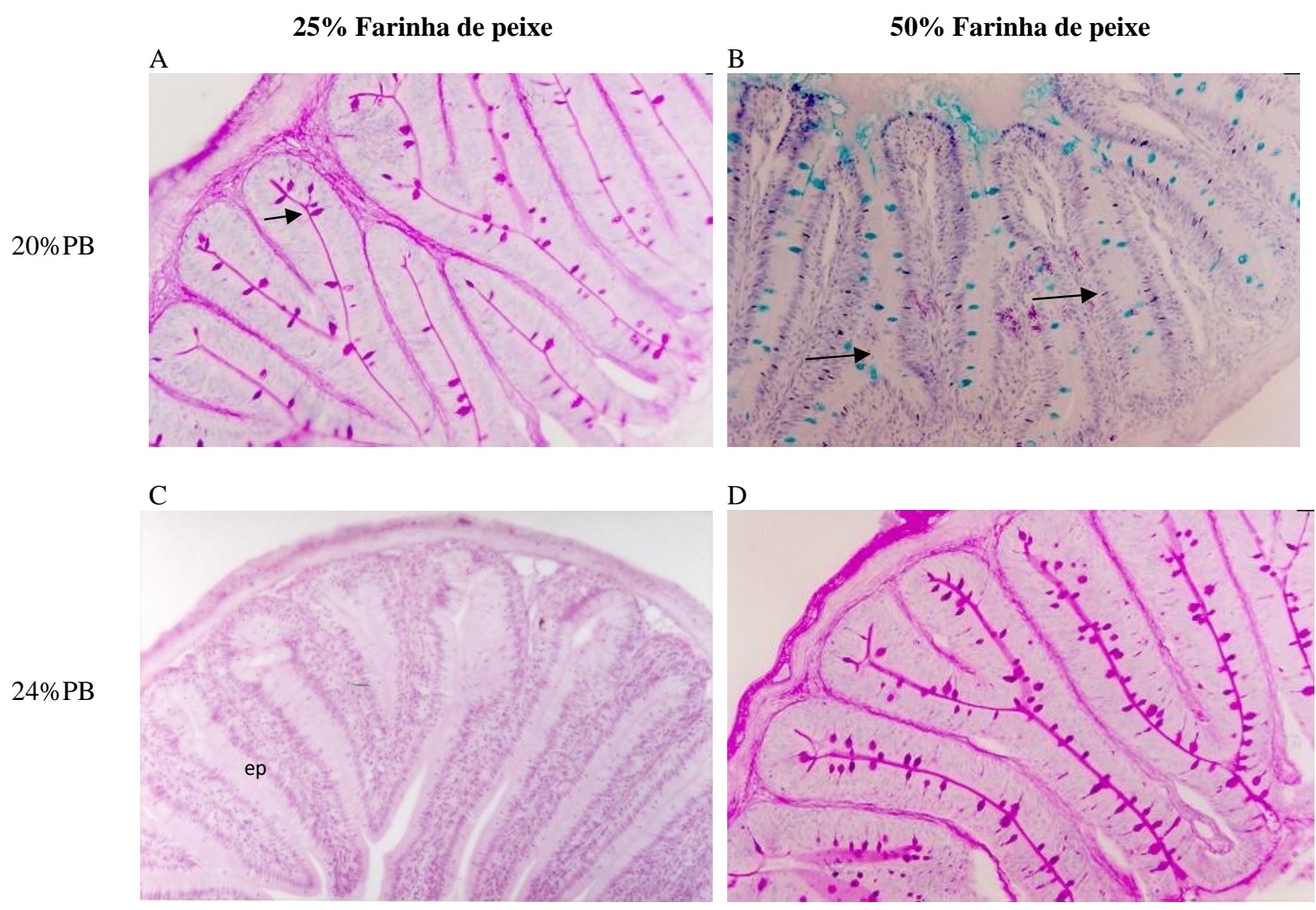

$\mathrm{E}$

$28 \% \mathrm{~PB}$

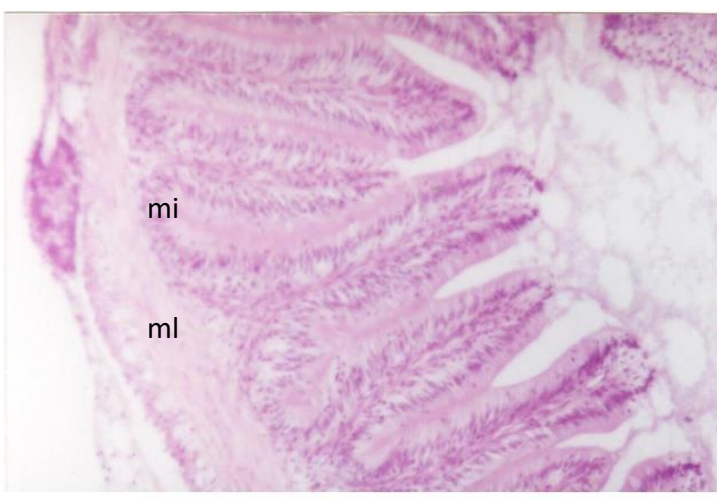

$\mathrm{F}$

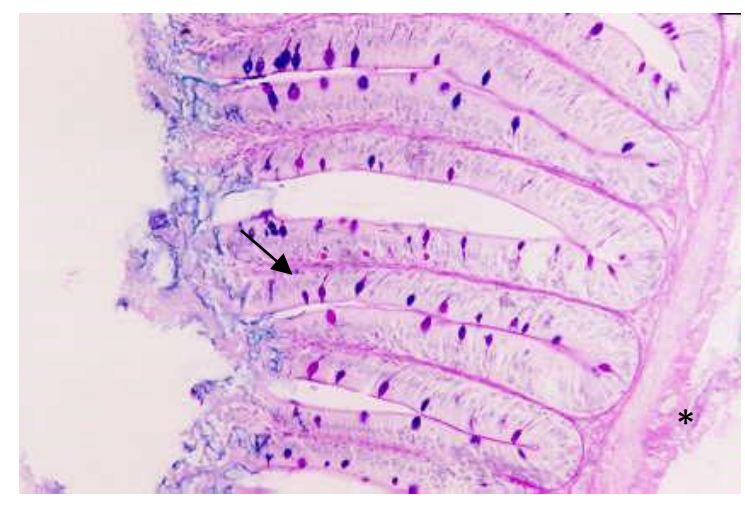

Figura 2. Fotomicrografia de intestino anterior (compreendendo a parte do jejuno em animais mamíferos) de tilápia do Nilo (Oreochromis niloticus). (A) 20\%PB 25\% FP, PAS/H células caliciformes (seta); (B) 20\%PB 50\% FP, AB pH 0,5 células caliciformes AB positiva (seta); (C) 24\% PB 25\% FP, H/E epitélio de revestimento (ep); (D) 24\% PB 50\% FP, PAS/H; (E) 28\% PB 25\% FP, H/E muscular longitudinal (ml), camada muscular interna (mi), (F) 28\%PB 50\% FP, PAS/AB serosa (*), células caliciformes glicoconjugadas (seta). (X200).

A inclusão da FP em $25 \%$ da proteína apresentou um pool de aminoácidos inadequado, só suprido com a elevação da PB das dietas. Enquanto a dieta com a inclusão da FP em 50\% da proteína apresentou no tratamento $28 \% \mathrm{~PB}$ algum desbalanceamento no perfil de aminoácidos, toxidade ou antagonismo nos sítios de absorção. Khalifa et al. (2018) reportaram que a diminuição da farinha de peixes em dietas para tilápia do Nilo reduziu os parâmetros de crescimento e de utilização dos nutrientes. Estes resultados são consequência da disponibilidade dos aminoácidos das dietas que darão suporte ao crescimento dos peixes (Koch et al., 2016). A resposta de diminuição dos índices de crescimento devido à sobrecarga de proteína da dieta está associada principalmente à sobrecarga das funções hepáticas (Abdel-Tawwab et al., 2010) reflexo das alterações deletérias na estrutura do órgão (Fuentes-Quesada et al., 2018). 
Tabela 4. Análise da histomorfometria e histoquímica das células caliciformes do intestino de tilápia do Nilo (Oreochromis niloticus) alimentadas com diferentes dietas com farinha de peixe.

\begin{tabular}{|c|c|c|c|c|c|c|c|}
\hline \multirow{2}{*}{\multicolumn{2}{|c|}{$\begin{array}{l}\text { Níveis de proteína } \\
\text { Proporção de Farinha de } \\
\text { peixe }\end{array}$}} & \multicolumn{2}{|c|}{$20 \%$ PB } & \multicolumn{2}{|c|}{$24 \%$ PB } & \multicolumn{2}{|c|}{$28 \%$ PB } \\
\hline & & $25 \%$ & $50 \%$ & $25 \%$ & $50 \%$ & $25 \%$ & $\mathbf{5 0 \%}$ \\
\hline \multicolumn{2}{|c|}{ Altura da vilosidade } & $\begin{array}{c}16,07 \pm 6,0 \\
\mathrm{~B}\end{array}$ & $\begin{array}{c}15,54 \pm 2,8 \\
\mathrm{~B}\end{array}$ & $\begin{array}{c}21,62 \pm 2,6 \mathrm{~A} \\
\mathrm{~B}\end{array}$ & $\begin{array}{c}25,46 \pm 2,5 \\
\mathrm{~A}\end{array}$ & $\begin{array}{c}27,16 \pm 2,7 \\
\mathrm{~A}\end{array}$ & $\begin{array}{c}25,63 \pm 2,0 \\
\mathrm{~A} \\
\end{array}$ \\
\hline \multirow{3}{*}{ AB/PAS } & Neutra & + & + & ++ & + & +++ & + \\
\hline & Ácida & + & ++ & - & + & +++ & ++ \\
\hline & Conj. & ++ & ++ & ++ & + & + & ++ \\
\hline \multirow{3}{*}{$\mathrm{AB}$ pH 2,5} & Neutra & - & - & - & - & - & - \\
\hline & Ácida & + & + & ++ & ++ & +++ & +++ \\
\hline & Conj. & - & - & - & - & - & - \\
\hline \multirow{3}{*}{ AB pH 0,5 } & Neutra & - & - & - & - & - & - \\
\hline & Ácida & + & + & +++ & ++ & +++ & +++ \\
\hline & Conj. & - & - & - & - & - & - \\
\hline \multirow{3}{*}{ PAS } & Neutra & +++ & ++ & ++ & ++ & +++ & +++ \\
\hline & Ácida & - & - & - & - & - & - \\
\hline & Conj. & - & - & - & - & - & - \\
\hline
\end{tabular}

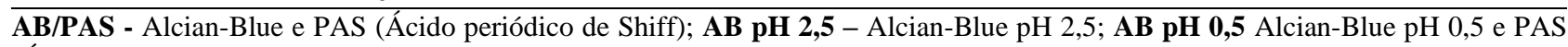
(Ácido periódico de Shiff).

$\mathrm{PB}$ - proteína bruta; Conj - células caliciformes com secreção conjugada.

Intensidade da reação: (+) fraca; (++) média; (+++) forte,

PFP - Proporção de Farinha de peixe: $25 \%$ do teor de proteína da dieta; $50 \%$ do teor de proteína da dieta.

Letras diferentes (maiúscula para níveis de proteína e minúscula proporção de farinha de peixe) reportam diferença significativa pelo teste de Tukey $(\mathrm{P}<0,05)$.

A diminuição da farinha de peixe em dietas para tilápia do Nilo não alterou a altura da vilosidade intestinal. No entanto, o aumento de proteína bruta da dieta refletiu em aumento da altura da vilosidade intestinal e maior desempenho dos peixes. O crescimento dos peixes é o reflexo da absorção de nutrientes no trato digestório (Ostaszewska et al., 2005; Romarheim et al., 2008). $\mathrm{O}$ aumento das vilosidades intestinais é o reflexo da adaptação dos peixes frente a produtos hidrolisados (Fuentes-Quesada et al., 2018, Murashita et al., 2018). A digestão intestinal depende da secreção de substâncias glicoproteicas das células caliciformes, da ação proteolítica do suco pancreático e também da digestão intracelular que está ligada à presença de glândulas gástricas (Dubaissi et al., 2014). A quantidade de células caliciformes no intestino de peixes está relacionada a diferentes alimentos utilizados, atividade bacteriana e das enzimas digestivas do trato digestório (Li et al., 2009). A secreção das células caliciformes foi influenciada pelo aumento do nível de proteína e pela maior proporção de farinha de peixe. Estes resultados podem ser reflexo de adaptações do trato digestório em absorver maior quantidade de nutrientes disponibilizado. Honorato et al. (2014) descreveram a mudança na secreção das células caliciformes de peixes suplantados com produtos hidrolisado com maior quantidade de aminoácidos livres.

Evidenciou-se que a diminuição da farinha de peixe em dietas para juvenis de tilápia do Nilo é possível e uma opção nas dietas com maior nível de proteína $(28 \% \mathrm{~PB})$, pois não afetou a desempenho zootécnico e a composição corporal dos peixes. As adaptações morfológicas e de secreção do trato digestório são ferramentas que possibilitam a tomada de decisão sobre aproveitamento da dieta ofertada.

É necessário, também, realizar um estudo de viabilidade econômica da diminuição da farinha de peixe em dietas para peixes, principalmente em fases de cultivo mais avançadas (crescimento e terminação), pois, atualmente, o custo deste ingrediente limita sua utilização. 


\section{Conclusão}

A farinha de peixe pode ser diminuída para $25 \%$ da proporção da farinha de peixe nas dietas com $28 \%$ de proteína bruta para juvenis de tilápia do Nilo.

\section{Conflito de Interesse}

Os autores declaram não existir conflito de interesse.

\section{Comitê de Ética}

Os procedimentos experimentais adotados neste estudo foram aprovados pelo Comitê de Ética no Uso de Animais (CEUA) sob o protocolo 003/14, do Centro Universitário da Grande Dourados/CEUA.

\section{Referências}

Abdel-Tawwab, M.; Ahmad, M.H.; Khattab, Y.A.E.; Shalaby, A.M.E. Effect of dietary protein level, initial body weight, and their interaction on the growth, feed utilization, and physiological alterations of Nile tilapia, Oreochromis niloticus (L.). Aquaculture, 298: 267-274, 2010.

Assano, M.; Muñoz Ramirez, A.P.; Stech, M.R.; Honorato, C.A.; Malheiros, E.B.; Carneiro, D.J. Desempenho de tilápia-do-Nilo cultivadas em viveiros alimentadas com diferentes fontes e níveis protéicos. Ensaios e Ciência, 15(5): 8190, 2011.

AOAC. Association of Official Analytical Chemists. Official methods of analysis of the Association of Official Analytical Chemists. $17^{\text {th }}$ ed. Gaithersburg: AOAC, 2000.

Awad, E.; Austin, D.; Lyndon, A. R. Effect of black cumin seed oil (Nigella sativa) and nettle extract (Quercetin) on enhancement of immunity in rainbow trout, Oncorhynchus mykiss (Walbaum). Aquaculture, 388-391(1): 193-197, 2013.

Boscolo, W.R.; Hayashi, C.; Meurer, F.; Martins, C.S. Farinha de peixe, carne e ossos, vísceras e crisálida, como atractantes em dietas para alevinos de tilápia do Nilo (Oreochromis niloticus). Revista Brasileira de Zootecnia, 30(5): 1397-1402, 2001.

Boscolo, W.R.; Hayashi, C.; Feiden, A.; Meurer, F.; Signor, A.A. Composição química e digestibilidade aparente da energia e nutrientes da farinha de resíduos da filetagem de tilápias, para a tilápia do Nilo (Oreochromis niloticus). Ciência Rural, 38(9): 2579-2586, 2008.
Cyrino, J.E.P.; Bicudo, Á.J.A.; Sado, R.Y.; Borghesi, R.; Dairiki, J.K. A piscicultura e o ambiente - o uso de alimentos ambientalmente corretos em piscicultura. Revista Brasileira de Zootecnia, 39: 68-87, 2010.

Deng, J.; Wang, K.; Mai, K.; Chen, L.; Zhang, L.; Mi, H. Effects of replacing fish meal with rubber seed meal on growth, nutrient utilization, and cholesterol metabolism of tilapia (Oreochromis niloticus $\times O$. aureus). Fish Physiology and Biochemistry, 43(4): 941-954, 2017.

Dubaissi, E.; Rousseau, K.; Lea, R.; Soto, X.; Nardeosingh, S.; Schweickert, A.; Amaya, E.; Thornton, D.J.; Papalopulu, N. A secretory cell type develops alongside multiciliated cells, ionocytes and goblet cells, and provides a protective, anti-infective function in the frog embryonic mucociliary epidermis. Development, 141(7): 1514-1525, 2014.

Fuentes-Quesada, J.P.; Viana M.T.; Rombenso, A.N.; Guerrero-Rentería Y.; Nomura-Solísc, M.; Gomez-Called, V.; Lazoa, J.P.; MataSotrese, J.A. Enteritis induction by soybean meal in Totoaba macdonaldi diets: Effects on growth performance, digestive capacity, immune response and distal intestine integrity. Aquaculture, 495: 78-89, 2018.

Han, D.; Shan, X.; Zhang, W.; Chen, Y.; Wang, Q.; $\mathrm{Li}, \mathrm{Z}$; Mai, K. A revisit to fishmeal usage and associated consequences in Chinese aquaculture. Reviews in Aquaculture, 10(2): 493-507, 2018.

Honorato, C.A.; Da Cruz, C.; Carneiro, D.J.; Machado, M.R.; Nascimento, C.A.; Saturnino, K.C. Histologia do fígado de tilápia do Nilo (Oreochromis niloticus) alimentados com dietas contendo silagem biológica de pescado. Pesquisa Veterinária Brasileira, 34: 64-68, 2014.

Khalifa, N.S.A.; Belal, I.E.H.; El-Tarabily, K. A.; Tariq, S.; Kassab, A.A. Evaluation of replacing fish meal with corn protein concentrate in Nile tilapia Oreochromis niloticus fingerlings commercial diet. Aquaculture Nutrition, 24(1): 143-152, 2018.

Koch, J.F.; Rawles, S.D.; Webster, C.D.; Cummins, V.; Kobayashi, Y.; Thompson, K.R.; Gannam, A.L.; Twibell, R.G.; Hyde, N.M. Optimizing fish meal-free commercial diets for Nile tilapia, Oreochromis niloticus. Aquaculture, 452: 357-366, 2016. 
Li, P.; Mai, K.; Trushenski, J.; Wu, G. New developments in fish amino acid nutrition: towards functional and environmentally oriented aquafeeds. Amino Acids, 37(1): 4353, 2009.

Moutinho, S.; Martínez-Llorens, S.; Tomás-Vidal, A.; Jover-Cerdá, M.; Oliva-Teles, A.; Peres, H. Meat and bone meal as partial replacement for fish meal in diets for gilthead seabream (Sparus aurata) juveniles: Growth, feed efficiency, amino acid utilization, and economic efficiency. Aquaculture, 468(1): 271-277, 2017.

Murashita, K.; Matsunaria, H.; Furuita, H.; Rønnestad, I.; Oku, H.; Yamamoto, T. Effects of dietary soybean meal on the digestive physiology of red seabream Pagrus major. Aquaculture, 493: 219-228, 2018.

NRC (National Research Council). Nutrient requirements of fish and shrimp. Washington, D.C.: National Academic Press, 2011. 390p.

Ostaszewska, T.; Dabrowski, K.; Palacios, M.E.; Olejniczak, M.; Wieczorek, M. Growth and morphological changes in the digestive tract of rainbow trout (Oncorhynchus mykiss) and pacu (Piaractus mesopotamicus) due to casein replacement with soybean proteins. Aquaculture, 245: 273-286, 2005.

Ota, E.C; Honorato, C.A.; Heredia-Vieira, S.C.; Flores-Quintana, C.I.; Castro Silva, T.S.; Inoue, L.A.K.A.; Cardoso, C.A.L. Hepatic and gastroprotective activity of Serjania marginata leaf aqueous extract in Nile tilapia (Oreochromis niloticus). Fish Physiology and Biochemistry, 45(3): 1051-1065, 2019.

Rodrigues, R.B.; Meurer, F.; Boscolo, W.R. Aditivos na nutrição de peixes. Revista Colombiana de Ciência Animal, 7(2): 228236, 2015.

Romarheim, O.H.; Zhang, C.; Penn, M.; Liu, Y.-J.; Tian, L.-X.; Skrede, A.; Krogdahl, A.; Storebakken, T. Growth and intestinal morphology in cobia (Rachycentron canadum) fed extruded diets with two types of soybean meal partly replacing fish meal. Aquaculture Nutrition, 14(2): 174-180, 2008. 